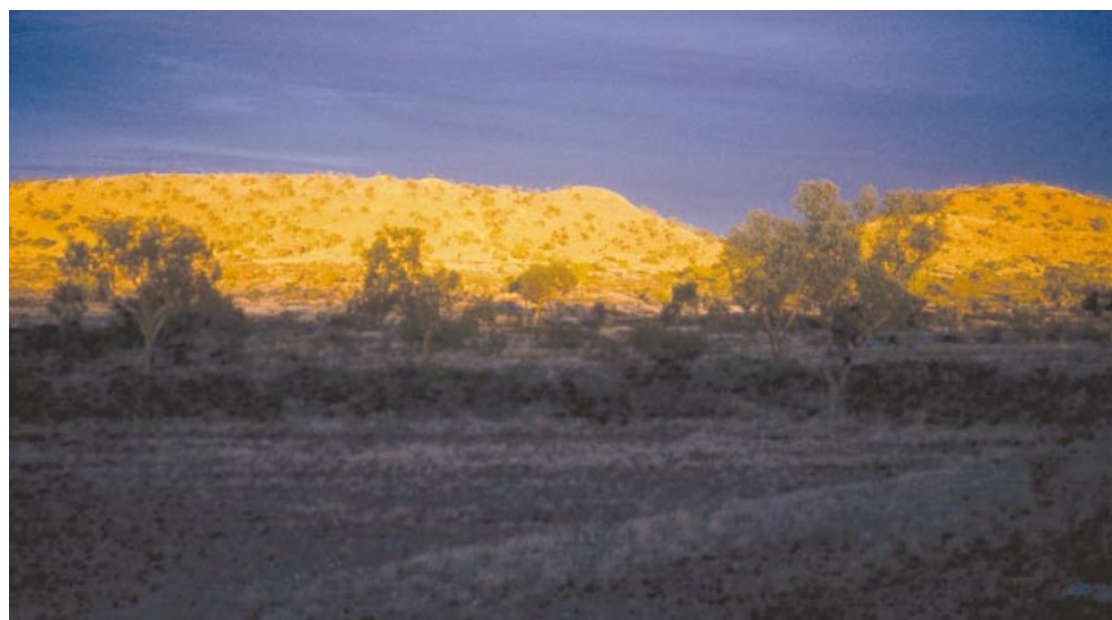

Figure 1 Marine exposure: the rocks of the Roper Group in Australia's Northern Territory reveal the oxidation state of Earth's oceans 1.5 billion years ago.

partitioning between relatively shallow, nearshore and presumably deeper, offshore environments in the Roper sediments: nearshore sediments are characterized by low DOP values, offshore sediments by high values. This indication of the existence of chemical gradients between the surface and deep ocean provides compelling evidence that the bottom waters of the middle Proterozoic oceans were euxinic and were overlain by oxic surface waters.

As to the sulphur isotope data, the authors argue that systematic differences in the isotopic composition of pyrite between coastal and oceanic sediments suggest that there were steep lateral gradients in sulphate concentration in the surface ocean. During bacterial sulphate reduction, a significant kinetic isotope effect (given as a value of 4-46\%o) occurs as anaerobic bacteria preferentially separate the lighter $S$ isotope that is, ${ }^{32} \mathrm{~S}$ versus ${ }^{34} \mathrm{~S}-$ during the production of sulphide and pyrite 5 . For this reason, sedimentary pyrite is commonly isotopically 'depleted' relative to sulphate of the same age.

The extent of this depletion is controlled in part by the availability of sulphate. Under non-limiting sulphate concentrations, sulphate-reducing bacteria have a big pool of sulphate from which to extract the lighter ${ }^{32} \mathrm{~S}$, and larger fractionations (around 45\%o) typically occur. By contrast, under sulphatelimiting conditions, two things can happen. First, as sulphate-reducing bacteria preferentially consume the light ${ }^{32} \mathrm{~S}$ in forming pyrite, the residual sulphate reservoir becomes enriched in ${ }^{34} \mathrm{~S}$. Second, as sulphate concentrations drop below a certain level, bacteria lose their ability to discriminate between sulphur isotopes, and therefore fractionations decrease ${ }^{6}$. The overall effect of sulphate limitation is a more enriched sulphur isotope signal.

Shen et al. discovered that the sulphur isotopic composition of pyrites in the Roper
Basin varies consistently along the palaeoenvironmental onshore-offshore transect. Offshore sediments display a wide distribution of sulphur isotopes (around 45\%o) that is comparable to maximum fractionation by sulphate-reducing bacteria. The authors attribute this distribution to a combination of pyrite formation in the water column under non-limiting sulphate concentrations, and pyrite formation in the sediments under sulphate-limiting conditions. By contrast, they found that the sulphur isotopic compositions of near-coastal pyrites are more enriched (relative to offshore values) and have a narrower distribution. This implies that bacterial sulphate reduction was occurring in a sulphate-limiting environment and that oceanic sulphate concentrations were diminished in coastal versus offshore surface waters. They suggest

\author{
Donald P. Bottaro and Lance A. Liotta
}

W hen cells are starved of oxygen, they usually die. This is why numerous anti-cancer treatments aim to prevent the growth of blood vessels in tumours, thereby cutting off their oxygen supply. But, in the latest addition to a long list of lessons we are learning about the insidious nature of cancer, it seems that tumours may in fact turn a lack of oxygen to their advantage. Pennacchietti and colleagues ${ }^{1}$, writing in Cancer Cell, have uncovered a molecular pathway that is switched on by low oxygen levels, and which could cause cancers to become more aggressive that, for a sulphate concentration gradient to have existed between coastal and oceanic waters, sulphate levels in the middle Proterozoic ocean must have been low.

Overall, Shen and colleagues' iron speciation data are fairly convincing in indicating that the Roper Basin contained euxinic bottom waters overlain by oxic surface waters. As they point out, however, research on other marine sediments of Proterozoic age will be needed to find out how geographically widespread this state of affairs was. And it remains to be seen what produced the systematic differences in sulphur isotopes along the transect. Were the enriched values and decreased fractionations in the nearshore settings indeed the result of a coastal region with a sulphate-minimum zone? Or did they result from pyrite formation in nearshore sediments, where sulphate diffusion was inhibited because the Proterozoic ocean lacked sediment-disturbing macrofauna, and contained uniformly lower sulphate concentrations than today? Whatever the answers, Shen et al. have produced a rich collection of data that set the standard for future studies.

Matthew T. Hurtgen is in the Department

of Geosciences and Penn State Astrobiology

Research Center, 801 Deike Building,

Pennsylvania State University, University Park,

Pennsylvania 16802, USA.

e-mail:mhurtgen@geosc.psu.edu

1. Canfield, D. E. Nature 396, 450-453 (1998)

2. Shen, Y., Knoll, A. H. \& Walter, M. R. Nature 423, 632-635 (2003)

3. Logan, G. A., Hayes, J. M., Hieshima, G. B. \& Summons, R. E Nature 376, 53-56 (1995).

4. Raiswell, R. \& Canfield, D. E. Am. J. Sci. 298, 219-245 (1998).

5. Kaplan, I. R. \& Rittenberg, S. C. J. Gen. Microbiol. 34, 71-91 (1964).

6. Habicht, K. S., Gade, M., Thamdrup, B., Berg, P. \& Canfield, D. E. Science 298, 2372-2374 (2002)

\title{
Cancer \\ Out of air is not out of action
}

Starving cancers of oxygen would seem to be a good way of killing them, but the presence of oxygen-deprived areas in tumours appears to correlate with poor prognosis. A molecular explanation for this has now been found.

and invade surrounding tissues.

Normal tissues receive a constant supply of oxygen from oxygenated haemoglobin molecules, carried by a continuous flow of blood. When such tissues are subjected to oxygen starvation (hypoxia) - because of a reduction either in blood flow or in the oxygen content of the blood - the eventual result is cell death. Depending on their individual metabolic requirements, some tissues can survive a hypoxic state for longer than others; for example, brain tissue can survive if hypoxia is limited to only a few minutes. To ensure survival, tissues react in two ways: 


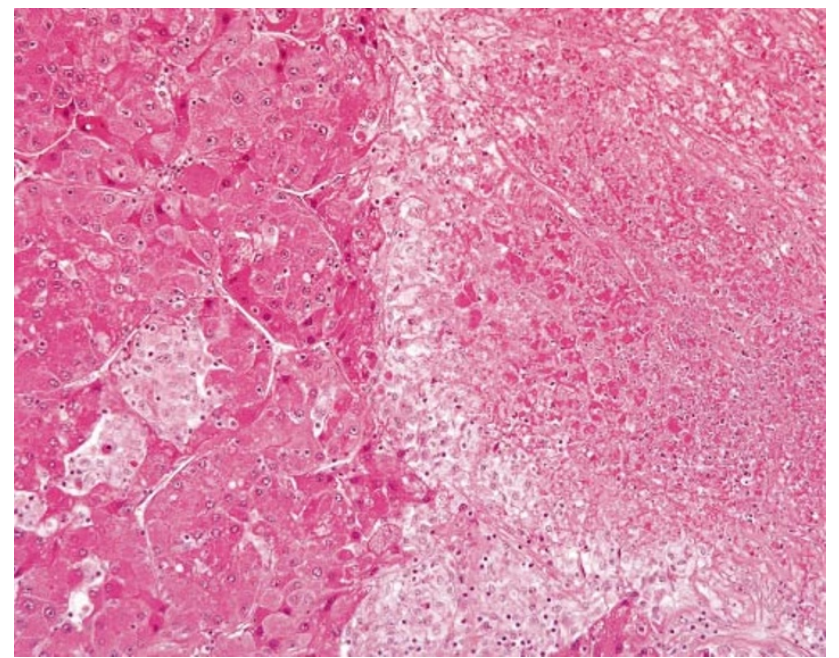

Figure 1 Short of oxygen. The left half of this section of a normal oxygen supply; the right half did not, and is dying. The cells in the right half are shrivelled and fragmented. human tumour had a they switch into a protective mode by using a specific set of hypoxia-sensing proteins called hypoxia-inducible factors, or HIFs; and they produce 'angiogenesis' proteins that will attract new blood vessels as a way of restoring local blood flow.

Hypoxia has found a place on both sides of the war on cancer. On the one hand, the idea that depriving a primary tumour of essential nutrients and oxygen will stop its growth and spread has won wide appeal. When tumours reach a certain size they outgrow their blood supply, and various studies have linked the resulting hypoxia, via HIFs, to the production of vascular endothelial cell growth factor and consequent stimulation of blood-vessel growth (Figs 1, 2). Following these findings, advocates of anti-angiogenesis strategies have looked for ways to block this molecular cascade by targeting the constituent signalling molecules or the responsive blood-vessel cells (endothelial cells) ${ }^{2,3}$. On the other hand, several clinical studies ${ }^{4}$ have shown that the presence of hypoxic regions within tumours correlates with poor prognosis and an increased risk of spread to other parts of the body (metastasis), irrespective of treatments used. These findings have cast a different light on tumour starvation as a therapeutic strategy.

Several biological mechanisms have been proposed to explain the observed correlation between hypoxia and accelerated cancer progression. But although there is indirect evidence for these mechanisms, discrete causal links between hypoxia and tumour aggressiveness have been elusive. The report by Pennacchietti et al. ${ }^{1}$ finally makes a firm molecular connection.

Pennacchietti et al. looked at the c-Met protein, which is a receptor for hepatocyte growth factor (HGF), and is found on the cell surface. In a nutshell, they show that when the HIF proteins sense hypoxia, they trigger an increase in the levels of c-Met. The authors first found that hypoxia led to higher levels of c-Met messenger RNA, indicating protein synthesis, and of c-Met protein in cultured tumour cells. They also identified regions of the c-Met gene that contain typical sequences for binding HIF, and showed that these sequences could be used to drive the expression of a different gene (a so-called reporter gene) in response to hypoxia. Next, the authors turned to grafted tumours in animals and to specimens of human tumours, and found that c-Met and one type of HIF protein were expressed in the same cells. The expression of HIFs is usually taken to indicate hypoxia. In the same samples, the expression of the endothelial-cell marker CD31 and c-Met was spatially distinct. This implies that regions of a tumour that are close to blood vessels (and so probably have normal oxygen levels) express less c-Met.

It is $\mathrm{known}^{5}$ that, when HGF binds to
c-Met, it switches on the receptor's intrinsic enzymatic activity and causes it to phosphorylate itself. This addition of phosphate groups stabilizes c-Met's catalytic activity and allows intracellular signalling proteins, such as Gab1, to latch on and also be phosphorylated. Pennacchietti et al. now show that, in cultured cells, hypoxia leads to enhanced HGF-induced phosphorylation of c-Met and Gab1. It also results in greater HGF-stimulated cell motility, invasion and branching. But hypoxia-enhanced, HGFstimulated cell branching is lost when c-Met is repressed.

So, hypoxia leads to increased c-Met levels in tumours, and to increased activity of this signalling pathway (Fig. 2). But why should that influence the aggressiveness of cancer? HGF, the ligand for c-Met, normally stimulates growth, migration and shape changes in a range of cells, including epithelial, endothelial, blood, neural and skin cells, as well as hepatocytes (liver cells) ${ }^{6}$. These diverse effects are crucial to development, organ growth and tissue regenera$\operatorname{tion}^{7-11}$. But overactive HGF signalling has also been linked to many different cancers ${ }^{11}$. For instance, inherited activating mutations in the gene encoding c-Met are associated with renal papillary carcinomas in humans ${ }^{12,13}$. This is probably partly because activation of the c-Met pathway by HGF stimulates cell division. But it is also known to cause the dissociation of one cell from another, increased cell mobility, and greater production of protease enzymes that degrade the matrix in which cells are embedded - all features that increase the ability of cells to migrate through the extracellular matrix in vitro, and which correlate

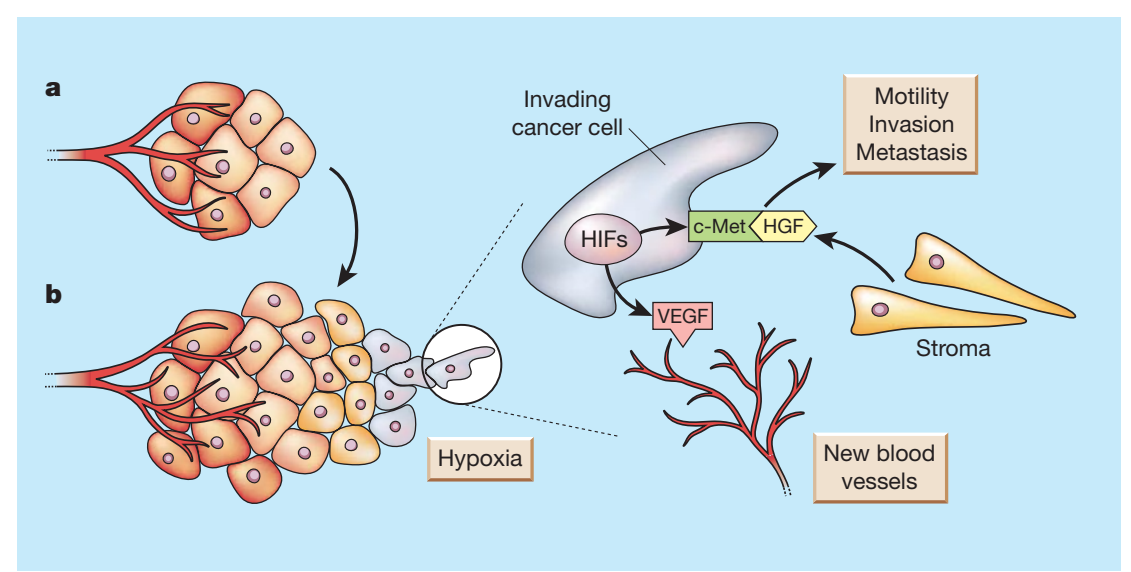

Figure 2 How tumours cope with — and can benefit from - a lack of oxygen. a, At this stage, the growing tumour is well supplied with oxygen and nutrients by its own blood supply. b, The tumour has now outgrown its blood supply and cells at the front line are becoming hypoxic. However, this need not always mean cell death, as is shown on the right. Hypoxia-inducible factors (HIFs) sense the low oxygen levels and stimulate the production of vascular endothelial growth factor (VEGF), a protein that attracts new blood vessels. As shown by Pennacchietti et al. ${ }^{1}$, HIFs also lead to higher levels of c-Met protein. This protein, on binding hepatocyte growth factor (HGF, which can be produced by nearby stromal cells), can result in increased cell motility, invasion and metastasis. These findings raise concerns about the idea of treating cancer by cutting off its blood supply. 
with tumour metastasis in vivo ${ }^{11}$. So the newly discovered connection between hypoxia and c-Met may explain why hypoxia often correlates with a poor prognosis for cancer patients.

This connection also sheds new light on a type of renal-cell carcinoma ${ }^{14}$. c-Met is reportedly overexpressed in these carcinomas, which are associated with inherited inactivating mutations in the von HippelLindau (VHL) gene. The VHL protein usually targets HIF proteins for degradation when oxygen levels are normal. So, when VHL is mutated, HIF can no longer be degraded, presumably leading to increased c-Met expression. In effect, the loss of VHL mimics hypoxia, and this can contribute to tumour aggressiveness.

The findings of Pennacchietti and colleagues $^{1}$ raise concerns about treatments that aim to cut off a tumour's blood supply. Although the resulting hypoxia might starve the main mass of the tumour, it could also stimulate the motility, invasion and metastasis of tumour cells at the front line the tumour-host interface. In other words, tumour cells that survive the hypoxia might be selected for increased aggressiveness. But perhaps there is a silver lining to this cloud, if anti-angiogenesis strategies could be combined with drugs that target the proteins needed for motility and invasion - which now include HGF and c-Met. Such an approach would circumvent the insidious ability of tumour cells to co-opt, and be sustained by, the hypoxia-induced programme of events.

Donald P. Bottaro is in the Urologic Oncology

Branch, and Lance A. Liotta is in the Invasion and

Metastasis Section, Laboratory of Pathology,

National Cancer Institute, National Institutes of

Health, Bethesda, Maryland 20892-1500, USA.

e-mail: liottal@mail.nih.gov

1. Pennacchietti, S. et al. Cancer Cell 3, 347-361 (2003).

2. Ferrara, N. Semin. Oncol. 29, 10-14 (2002).

3. Jain, R. K. Semin. Oncol. 29, 3-9 (2002).

4. Hockel, M. \& Vaupel, P. Semin. Oncol. 28, 36-41 (2001).

5. Bardelli, A. \& Comoglio, P. M. Ciba Found. Symp. 212, 133-144 (1997).

6. Michalopoulos, G. K. \& DeFrances, M. C. Science 276, 60-66 (1997).

7. Birchmeier, C. \& Gherardi, E. Trends Cell Biol. 8, 404-410 (1998).

8. Streit, A. C. \& Stern, C. D. Ciba Found. Symp. 212, 155-165 (1997)

9. Birchmeier, W. et al. Ciba Found. Symp. 212, 230-240 (1997). 10. Funakoshi, H. \& Nakamura, T. Clin. Chim. Acta 327, 1-23 (2003)

11.Zhang, Y. W. \& Vande Woude, G. F. J. Cell. Biochem. 88, 408-417 (2003).

12. Schmidt, L. et al. Nature Genet. 16, 68-73 (1997).

13. Jeffers, M. et al. Proc. Natl Acad. Sci. USA 94, 11445-11450 (1997)

14. Maranchie, J. K. et al. Cancer Cell 1, 247-255 (2002).

Condensed-matter physics

\title{
Hydrogen falls into line
}

\author{
Richard M. Martin and Giulia Galli
}

Hydrogen ions, both positive and negative, have a pervasive influence on the properties of materials and solutions. A unified picture of the behaviour of these ions has now been drawn.

$\mathrm{T}$ he role of hydrogen in controlling electrochemical activity is essential to your life and to the life of your computer. The former is well known to any student of chemistry, as the $\mathrm{pH}$ of aqueous solutions is defined by the concentration of $\mathrm{H}^{+}$ions. The crossover from a dominance of $\mathrm{H}^{+}$to $\mathrm{OH}^{-}$defines the transition from acidic to alkaline solutions, which has profound consequences for chemical and biological processes. Perhaps less well known is that hydrogen is also essential for the operation and lifetime of every modern solid-state electronic device. The ability of hydrogen to take on either of two charge states, $\mathrm{H}^{+}$or $\mathrm{H}^{-}$, means that it can 'passivate' electrically active defects of either sign in the device material. Introducing hydrogen into the processing makes it possible to achieve the perfection required to reliably produce millions of transistors on a chip. On page 626 of this issue, Van de Walle and Neugebauer ${ }^{1}$ propose that these two phenomena are closely related: in fact, they claim to have found a universal alignment of the electro- chemical level for the change of charge state of hydrogen complexes across a wide range of materials.

Why should there be any relation between the $\mathrm{H}^{+}$and $\mathrm{OH}^{-}$ions solvated in liquid water and the hydrogen bound to defects in strongly bonded solids? In the case of water, the role of the solvation shell around the ion has been the subject of studies for many years; the details are still obscure, but interesting suggestions are emerging from simulations that start from first principles $^{2,3}$. In the case of semiconductors, the mechanism of hydrogen passivation has been elucidated (see, for example, ref. 4), and the structures of the passivated defects vary greatly for different materials. How could such variety be captured in a 'universal' relation?

The proposal made by Van de Walle and Neugebauer ${ }^{1}$ is based on calculations done using state-of-the-art methods including 'density functional theory'). The authors are able to predict a large range of formation energies of the individual defect

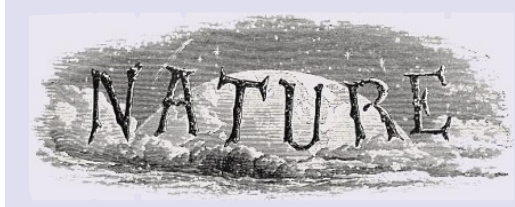

100 YEARS AGO

The condition of the German Antarctic Expedition which, under the command of Dr. von Drygalski, left Germany in August, 1901 , is causing great anxiety... It will be remembered, a correspondent of the Pall Mall remarks, that a station was erected on Kerguelen Island in January, 1902, which was intended to serve as a place of observation and as a base for the expedition ship Gauss, which was to penetrate much farther south. Those who were at the station, however, suffered terribly from the climate, and then were attacked by beri-beri, which appears to be endemic in that part of the world... The Gauss sailed south, but as nothing has been heard of her for a long time it is feared that she is lost, and doubts have been expressed that any of her present officers and crew will ever be heard of again. ALSO...

Mr. Marconi is reported to have said on his return to England last week that it will be another six weeks before Transatlantic communication will be resumed. The precise nature of the breakdown has not been published. The American company proposes to extend greatly the system in America by establishing new stations in New York and on the great lakes. It is also stated that the report that Mr. Marconi was suffering from nervous breakdown and would have to take a prolonged rest is unfounded.

From Nature 4 June 1903.

\section{YEARS AGO}

When an impulse arrives at a motor end-plate, it causes acetylcholine to be released at numerous 'key points' and in discrete quanta, each containing a large number of molecules. The discharge of each quantal unit is an all-or-none event, and its success or failure is subject to independent statistical fluctuation. Its chances can be altered by various means, for example, by changing the ionic environment. Even under normal conditions, the probability of an individual 'quantum response' appears to be less than unity; that is, a nerve impulse excites at each junction only a fraction of the whole synaptic population. By lowering the calcium and raising the magnesium concentration, the chance of any one unit responding to a nerve impulse can be reduced to a very low value, and under these conditions, which apply to all the experiments described below, the statistical nature of the transmission process can be demonstrated most effectively. J. del Castillo, B. Katz From Nature 6 June 1953. 